\title{
Pharmaceutical Quality/CMC Validation Parameter Terminology
}

National Cancer Institute

\section{Source}

National Cancer Institute. Pharmaceutical Quality/CMC Validation Parameter

Terminology. NCl Thesaurus. Code C133870.

A category of terminology used to qualify the information pertaining to validation parameters in the framework of the Pharmaceutical Quality/Chemistry, Manufacturing and Controls documents. 